\title{
非整数階微分を利用した地殼内流動の数値シミュレーション法開発
}

\section{Numerical Simulation of non-Fickian Diffusion in a Fractured Porous Aquifer}

\author{
○千葉 隆一（東北大院・環境）, Sergei FOMIN(California State Univ.), \\ Vladimir CHUGUNOV(Kazan State Univ.)，新堀 雄一（東北大院・工），正 橋田 俊之（東北大院・工） \\ Ryuichi CHIBA, Fracture and Reliability Research Institute, Graduate School of Engineering, Tohoku University, Japan \\ Sergei FOMIN, California State University, Chico, USA \\ Vladimir CHUGUNOV, Kazan State University, Kazan, Russia \\ Yuichi NIIBORI, Graduate School of Engineering, Tohoku University, Sendai, Japan
}

Toshiyuki HASHIDA, Fracture and Reliability Research Institute, Graduate School of Engineering, Tohoku University, Japan

Key Words: Fractional derivative, Solute transport, Numerical simulation

\section{緒言}

現在，一般的に利用されている流動モデルは Fick 則を基 礎としているものが大半である。しかしながら，岩体を対 象とした解析では流動挙動の正確な予測が困難であるとい う指摘がなされている ${ }^{1)}$. この原因は, Fick則の前提が均質 な媒体であり，岩石のようにき裂が不規則に分布するため に巨視的に見た場合不均質となる媒体には適さないことに 由来するためであるとされている.

一方，そのような不均質媒体に対しては Fick 則によらな い流動モデルを適用することで精度の良い流動予測が可能 であることが報告されている ${ }^{2)}$ 。このとき, 方程式は非整数 階微分を含んだ偏微分方程式として記述される. 非整数階 微分上は微分の係数が整数以外にも拡張された微分であり，

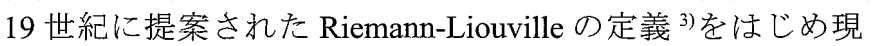
在までに複数提案されている。しかしながら，この非整数 階微分を用いた移流拡散モデルは一次元数学モデルによる 個々の現象の再現に留まり, 工学的に利用可能な流動予測 手法ではない。そこで, 本研究では実用的な流動予測手法 構築を目的として, 非整数階微分を利用した地殻内流動モ デルの開発を行う。

\section{非整数階微分を含む移流拡散方程式の 数值計算}

本研究では流動予測モデル構築にあたり, 非整数階微分 を含んだ一次元移流拡散方程式の数值シミュレーションコ 一ド開発を行った。一次元移流拡散モデルの概念図を Fig.1 に示す．これは多数のき裂により高い透水性を有する帯水 層（斜線部分）と, その周辺に存在する透水性の低い岩石 から構成されている. 物質は斜線部分の左端, $x=0$ から供 給され, 帯水層内を $x$ 方向に移動する. 帯水層内では $x$ 方向 への速度 $v$ の流れによる物質輸送， $x, y$ 方向それぞれへの 拡散，および帯水層内部での吸着等が作用しているが，特 に移流による物質輸送が支配的である。一方, 岩石部分で は $x, y$ 方向それぞれへの拡散が作用しているが，y方向へ の拡散が支配的であるものとする。

このときの帯水層内での移流拡散方程式を式 $(1)^{3)}$ に示す. 本研究では (aputo ${ }^{4}$ により定義された非整数階微分を用いた.

$$
\frac{\partial c}{\partial \tau}+\frac{\partial^{\gamma} c}{\partial \tau^{\gamma}}=-v \frac{\partial c}{\partial x}+D \frac{\partial}{\partial y}\left(\frac{\partial^{\alpha} c}{\partial y^{\alpha}}\right)+D \frac{\partial}{\partial x}\left(\frac{\partial^{\alpha} c}{\partial x^{\alpha}}\right)
$$

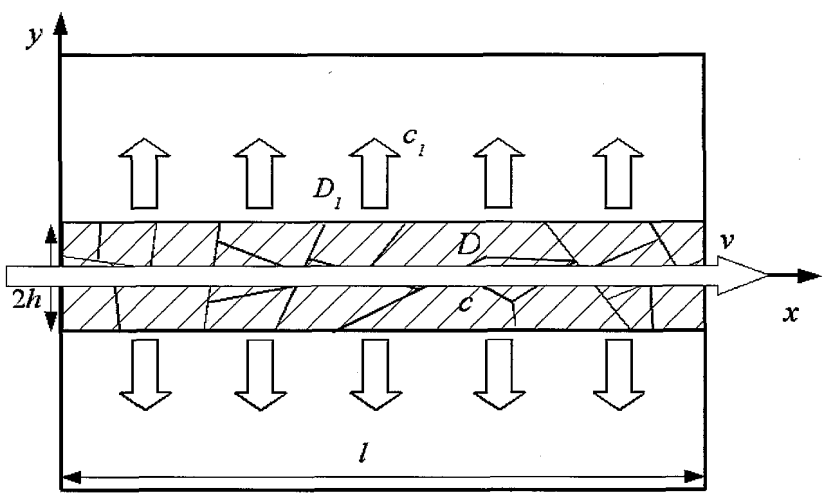

Fig.1 Schematic diagram of a fractured porous aquifer.

式(1)中の $c\left[\mathrm{ML}^{-3}\right]$ は帯水層内での濃度， $\tau[\mathrm{T}]$ は時間， $v\left[\mathrm{LT}^{-1}\right]$ は帯水層内での流速, $D\left[\mathrm{~L}^{1+a} \mathrm{~T}^{-1}\right]$ は帯水層での拡散係数であ る. 式中の $\alpha, \gamma$ は非整数階微分の微分係数であり, それぞ れ 0 から 1 の間の值をとる.

式(1)を無次元化することで以下の式(2)が得られる.

$\frac{\partial C}{\partial t}+b \frac{\partial^{\gamma} C}{\partial t^{\gamma}}+\frac{\partial^{\beta} C}{\partial t^{\beta}}=-\frac{\partial C}{\partial X}+\frac{1}{P e} \frac{\partial}{\partial X}\left(\frac{\partial^{\alpha} C}{\partial X^{\alpha}}\right)$

ここでPeはペクレ数である. 微分係数 $\alpha, \beta, \gamma$ はそれぞれ $x$ 方向への拡散, 帯水層から周囲の岩石への拡散, 帯水層に おける吸着などの影響に関連するパラメータとなっている.

本研究では数值シミュレーションに差分法を用いて計算 を行っている. 式(2)の左辺第二項, 第三項および右辺第二 項にある非整数階微分は以下のように二項定理を用いた方 法で差分化が可能である.

$$
\frac{\partial^{\alpha} f}{\partial x^{\alpha}} \approx \frac{1}{(\Delta x)^{\alpha}} \sum_{i=0}^{j+1} \frac{\Gamma(-\alpha+i)}{\Gamma(-\alpha) \Gamma(i+1)} f_{j-(i-1)} .
$$

本研究では Caputo の定義による非整数階微分であることを 考慮し, 濃度 $C$ を式(4)のように $U$ で置換したうえで式(3)を 適用し差分を行った.

$$
U=C-C_{0}(t)
$$

ここで, $C_{0}(t)$ は $X=0$ での濃度である. また, 右辺第一項の 移流項にはTVDスキーム6)用いた。以上より，式(2)は以 下のようになる。 


$$
\begin{aligned}
& \left\{\frac{1}{\Delta t}-\frac{b}{(\Delta t)^{\gamma}} G_{1}^{\gamma}-\frac{1}{(\Delta t)^{\beta}} G_{1}^{\beta}\right\}\left(U+C_{0}\right)_{j}^{n} \\
& -\sum_{i=2}^{n+1}\left\{\frac{b}{(\Delta t)^{\gamma}} G_{i}^{\gamma}+\frac{1}{(\Delta t)^{\beta}} G_{i}^{\beta}\right\}\left(U+C_{0}\right)_{j}^{n-(i-1)} \\
& -\left\{\frac{1}{\Delta t}+\frac{b}{(\Delta t)^{\gamma}} G_{0}^{\gamma}+\frac{1}{(\Delta t)^{\beta}} G_{0}^{\beta}\right\} \\
& =\left\{\frac{1}{\Delta t}+\frac{b}{(\Delta t)^{\gamma}} G_{0}^{\gamma}+\frac{1}{(\Delta t)^{\beta}} G_{0}^{\beta}\right\} U_{j}^{n+1} \\
& +\frac{1}{\Delta X}\left\{f_{j+1 / 2}^{n \tilde{+} 1}-f_{j-1 / 2}^{n \tilde{1} 1}\right\}+\frac{1}{P e} \frac{1}{(\Delta X)^{\alpha+1}} \sum_{i=2}^{j+1} G_{i}^{\alpha} U_{j-(i-1)}^{n+1} \\
& \text { ここで, } \\
& G_{i}^{\beta}=\frac{\Gamma(-\beta+i)}{\Gamma(-\beta) \Gamma(i+1)}, G_{i}^{\gamma}=\frac{\Gamma(-\gamma+i)}{\Gamma(-\gamma) \Gamma(i+1)}, \\
& G_{i}^{\alpha}=\frac{\Gamma(-(\alpha+1)+i)}{\Gamma(-(\alpha+1)) \Gamma(i+1)}
\end{aligned}
$$

である。

\section{計算結果}

開発した計算コードの妥当性を評価するために解析的に 得られた解との比較を行った。このときの計算条件は以下 の通りである.

$$
\begin{aligned}
& C(X, 0)=C_{0}(t)=1 \\
& C(0, X)=0 \\
& C(\infty, X) \rightarrow 0
\end{aligned}
$$

計算結果を Fig.2 に示す. 解析解は線で, 計算結果は点で 表されている。このとき，Pe=1， $\alpha=1$ である. Fig.2から， 計算結果は解析解之良く一致していることが確認できる. 従って，作成した計算コードは妥当なものであると考えら れる。また，Fig.2から確認できるように， $\gamma$ が 0 近いほど 濃度は全体的に減少する傾向が見られる。一方， $\gamma$ の変化に 伴う濃度減少に比べて物質の到達距離の変化は小さく, 拡 散距離への影響は小さいと考えられる。

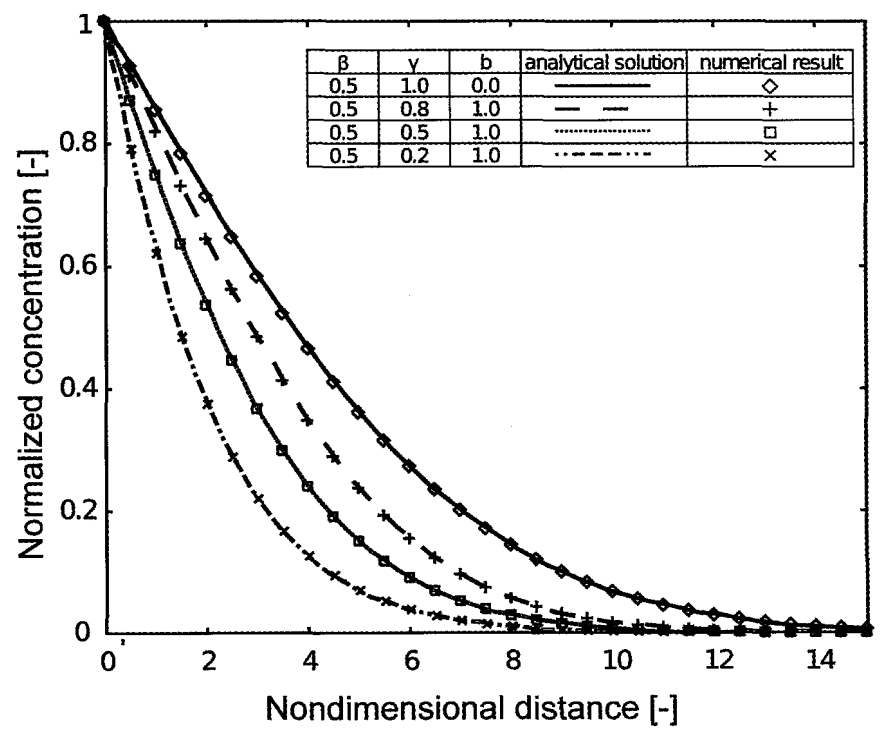

Fig.2 Comparison of analytical and numerical solution ( $t=15, P e$ $=1, \quad \alpha=1)$.

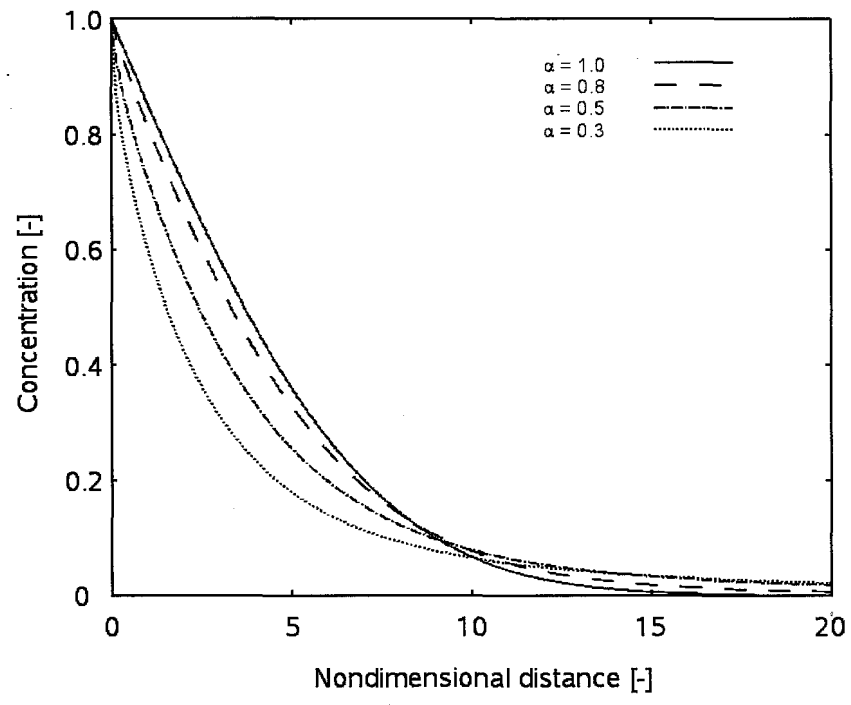

Fig.3 Distribution of concentration with respect to the $x$-direction at $t=15$ for different values of $\alpha(t=15, b=0, P e=1, \beta=0.5)$.

Fig. 3 は $\alpha$ を 0.3 から 1.0 まで変化させた場合での計算結 果である. 計算条件は先ほどと同様に式(7)の通りである.

Fig.3から確認できるように, $\alpha$ が 0 に近付くほど $X=0$ 近傍 での濃度は低下している. $X=10$ 以降では逆に $\alpha$ が 0 に近い ほど濃度は高くなり, 拡散距離が伸びる結果となっている。 Fig.2 と比較した場合, $\gamma$ に比べて $\alpha$ の変化は拡散距離への 影響が顕著なものとなっている。

\section{結言}

本研究では，複雑な地殼内流動の予測手法構築を目的と して非整数階微分を含んだ一次元移流拡散方程式の数值シ ミュレーションコードの開発を行った。計算ョードは二項 定理と変数の置換を考慮することで Caputo の定義による非 整数階微分の差分を可能とした。計算結果と解析解を比較 したところ両者は良い一致を見せ，作成した計算コードの 妥当性が示された. 微分係数 $\gamma$ は 0 に近い程濃度が全体的に 減少する事が確認された。一方， $\alpha$ の場合は $X=0$ 近傍では $\gamma$ と同様に濃度は減少するものの，同時に拡散距離が拡大す ることが確認された。

\section{参考文献}

1). A. A. Keller et al., "Prediction of single phase transport parameters in a variable aperture fracture", Geophis. Res. Lett., 22, 1995, pp.1425-1428.

2). D. A. Benson et al., "Application of a fractional advectiondispersion equation", Water Resour. Res., 36, 2000, pp.14031412.

3). M. Caputo, "Liner Models of Dissipation whose $Q$ is almost Frequency Independent-II", Geophys. J. R. astr. Soc., 13, 1967, pp.529-539.

4). S. Fomin et al., "The effect of non-Fickian diffusion into surrounding rocks on contaminant transport in a fractured porous aquifer", Proc. R. Soc. A, 461, 2005, pp.2923-2939.

5). S. G. Samko et al., "Fractional Integrals and Derivatives: Theory and Applications", Gordon and Breach, London, 1993.

6). H. C. Yee, and A. Harten, AIAA Journal, 25, 1987, pp.266274. 